\title{
PENENTUAN BATAS KUANTIFIKASI METODE PENGUJIAN LOGAM BERAT Cd, Cu, Mn, Zn DALAM AIR SECARA INDUCTIVELY COUPLE PLASMA TIME OF FLIGHT MASS SPECTROMETRY
}

\section{DETERMINING LIMIT OF QUANTITATION (LoQ) OF THE TESTING METHOD FOR HEAVY METALS Cd, Cu, Mn, Zn IN WATER USING INDUCTIVE COUPLE PLASMA TIME OF FLIGHT MASS SPECTROPHOTOMETRY (ICP-ToF-MS)}

\author{
Ely R. dan Anwar Hadi(1)
}

(Diterima tanggal 29 Mei 2017 Disetujui tanggal 18 September 2017)

\begin{abstract}
ABSTRAK
Logam berat $\mathrm{Cd}, \mathrm{Cu}, \mathrm{Mn}$, dan $\mathrm{Zn}$ dalam air atau air limbah dapat dianalisis dengan berbagai metode pengujian tergantung pada kadar analit dan tujuan yang ditetapkan. Salah satu metode pengujian logam berat pada kadar rendah hingga ng/L adalah Inductive Couple Plasma Time of Flight Mass Spectrophotometry (ICP-ToF-MS). Untuk mengetahui seberapa kecil kadar analit yang mampu dideteksi oleh ICP-ToF-MS, maka perlu ditentukan batas deteksi instrumen dan batas kuantifikasi. Batas deteksi instrumen ditentukan melalui 3 kali simpangan baku hasil pengukuran air bebas analit yang telah ditambahkan asam nitrat. Berdasarkan batas deteksi instrumen yang diperoleh, maka batas kuantifikasi dapat ditentukan melalui pengulangan kadar logam yang setara dengan 10 kali kadar batas deteksi instrumen. Batas deteksi instrumen diperoleh berturut-turut untuk logam $\mathrm{Cd}, \mathrm{Cu}, \mathrm{Mn}, \mathrm{dan} \mathrm{Zn}$ adalah $0,0006 \mu \mathrm{g} / \mathrm{L}, 0,002 \mu \mathrm{g} / \mathrm{L}, 0,002 \mu \mathrm{g} / \mathrm{L}$, dan $0,004 \mu \mathrm{g} / \mathrm{L}$ sedangkan batas kuantifikasi masing-masing 0,006 $\mu \mathrm{g} / \mathrm{L}, 0,02 \mu \mathrm{g} / \mathrm{L}, 0,02 \mu \mathrm{g} / \mathrm{L}$, dan $0,04 \mu \mathrm{g} / \mathrm{L}$. Dengan menetapkan batas kuantifikasi, laboratorium dapat melaporkan hasil pengujian disertakan ketidakpastian pengukuran pada kadar lebih dari batas kuantifikasi atau dilaporkan kurang dari batas kuantifikasi pada kadar rendah, sehingga pelaporan jadi bermakna.
\end{abstract}

Kata Kunci: Logam Cd, Cu, Mn, Zn, batas deteksi instrumen, batas kuantifikasi, ICP-ToF-MS

\begin{abstract}
Heavy metals $\mathrm{Cd}, \mathrm{Cu}, \mathrm{Mn}$, and $\mathrm{Zn}$ in water or waste water can be analyzed by various testing methods depend on the concentration of analyte and the intended purpose. One of the testing methods for heavy metals at low concentration until ng/L, is Inductively Couple Plasma Time of Flight Mass Spectrometry (ICP-ToF-MS). To know how small the concentration of analyte can be detected by ICP-ToF-MS, so instrumental detection limit (IDL) and limit of quantitation (LoQ) must be determined. IDL is determined by measuring 10 times of free analyte water which contained nitric acid. From the measurement, resulted standard deviation and then multiple 3 times so the value of IDL known. Based on the result of IDL which obtained by experiment, the limit of quantitation (LoQ) can be determined by the repeatability of heavy metals concentration at 10 times the IDL. The result of determining IDL of $\mathrm{Cd}, \mathrm{Cu}, \mathrm{Mn}$, and $\mathrm{Zn}$, are $0.0006 \mu \mathrm{g} / \mathrm{L}, 0.002 \mu \mathrm{g} / \mathrm{L}, 0.002 \mu \mathrm{g} / \mathrm{L}$, and $0.004 \mu \mathrm{g} / \mathrm{L}$, whereas LoQ respectively 0.006 $\mu \mathrm{g} / \mathrm{L}, 0.02 \mu \mathrm{g} / \mathrm{L}, 0.02 \mu \mathrm{g} / \mathrm{L}$, and $0.04 \mu \mathrm{g} / \mathrm{L}$. By determining the LoQ, a laboratory can report the test results including uncertainty of measurement at concentration more than $L o Q$ or be reported less of Lo $Q$ at low concentration, so that the reporting becomes meaningful
\end{abstract}

Keywords: Metal Cd, Cu, Mn, Zn, instrumental detection limit, limit of quantification, ICP-ToF-MS

\section{PENDAHULUAN}

Kadar logam dalam air permukaan atau air limbah dapat ditentukan dengan beberapa metode pengujian diantaranya gravimetri, kompleksometri, spektrofotometri UVVis, voltametri, AAS atau ICP-MS dan sebagainya. Pemilihan metode pengujian dan

${ }^{1}$ Pusat Penelitian dan Pengembangan Kualitas dan Laboratorium Lingkungan, BLI - KLHK, Kawasan PUSPIPTEK Gedung 210, Jl. Raya PUSPIPTEK Serpong Tangerang - Banten, telp/fak. 021-75631113, email: elyrahmy@yahoo.com 
peralatan yang digunakan sangat tergantung dari kadar analit logam dalam air dan tingkat sensitivitas yang dibutuhkan serta tujuan yang ditetapkan. Pengukuran dengan gravimetri atau kompleksometri dipilih karena merupakan metode primer, namun kadar analit logam dalam sampel air yang dianalisis relatif cukup besar yaitu memiliki satuan mg/L (ppm) atau lebih besar. Ketika kadar analit lebih kecil dari ppm, maka metode kompleksometri kurang optimal karena kesulitan penentuan titik ekivalen maupun titik akhir saat titrasi dilakukan. Sementara kesulitan menggunakan metode gravimetri yaitu saat penimbangan dilakukan, jika laboratorium hanya menggunakan timbangan analitik dengan ketelitian 0,1 $\mathrm{mg}$. Sehubungan dengan hal tersebut, metode pengujian dan peralatan yang lebih sensitif harus dipilih untuk pengujian air yang memiliki kadar analit logam dengan satuan $\mu \mathrm{g} / \mathrm{L}$ (ppb) bahkan ng/L (part per trilion, ppt). Mempertimbangkan hal tersebut, maka peralatan Inductive Couple Plasma-Mass Spectrophotometer (ICP-MS) dapat digunakan untuk pengujian analit logam dalam air pada kadar hingga satuan ng/L [1-3].

Peralatan ICP-MS memiliki batasan deteksi yang berbeda disebabkan perbedaan teknologi yang digunakan oleh pabrikan pembuat peralatan. Batasan kadar analit terendah yang mampu diukur oleh suatu instrumentasi sehingga menghasilkan deteksi signal cukup besar dan dapat dibedakan dengan signal blanko disebut lower limit detection (LLD), detection limit (DL) atau limit of detection (LoD). Dalam prakteknya, LoD jarang digunakan sebagai penentuan batasan terendah suatu metode pengujian disebabkan LoD masih dipengaruhi oleh noise dari instrumen sehingga mengakibatkan tingkat kesalahan yang masih relatif tinggi. Umumnya, rentang kerja terendah suatu metode pengujian ditentukan oleh batas kuantifikasi. Secara definisi, batas kuantifikasi adalah kadar analit yang menghasilkan signal lebih besar dari blanko pada kondisi kegiatan rutin yang dapat diterapkan di laboratorium. Batas kuantifikasi (limit of quantitation, LoQ, atau minimum quantitation level, $M Q L)$ merupakan suatu batasan terkecil hasil pengujian yang dapat dilaporkan (limit of reportable, LoR) dengan menyertakan ketidakpastian pengukuran. Dengan demikian, LoQ merupakan batas terendah dari rentang kerja pengujian yang dapat digunakan sebagai batasan terendah suatu pelaporan hasil [4-6].

Ketika peralatan baru diinstal di laboratorium, LoQ dapat ditentukan melalui instrumental detection limit (IDL) yang diinformasikan oleh pabrikan pembuat instrumentasi. Hal ini disebabkan, semua pabrikan pembuat instrumentasi mencantumkan nilai IDL yang digunakan sebagai informasi kinerja instrumen yang diproduksi dan sebagai bagian dari promosi teknisnya. Namun demikian, nilai IDL akan berubah seiring dengan waktu penggunaan instrumen tersebut. Semakin lama digunakan, instrumen akan mengalami depresiasi yang menyebabkan kurang sensitifnya instrumen tersebut. Oleh karena itu, laboratorium harus menentukan nilai IDL sesuai kemampuan sensitivitas instrumen saat LoQ akan ditentukan.

Berdasarkan penjelasan diatas, maka kajian ilmiah penentuan LoQ dilakukan untuk analit logam berat $\mathrm{Cd}, \mathrm{Cu}, \mathrm{Mn}, \mathrm{Zn}$ dalam air dengan menggunakan instrumen Inductive Couple Plasma - Time of Flight 
- Mass Spectrophotometer (ICP-TOF-MS). ICP-TOF-MS dipilih karena kadar analit logam berat sangat rendah dengan satuan $\mu \mathrm{g} / \mathrm{L}$ atau $\mathrm{ng} / \mathrm{L}$ dalam air. Adapun kajian dilakukan di laboratorium Pusat Penelitian dan Pengembangan Kualitas dan Laboratorium Lingkungan - Kementerian Lingkungan hidup, Serpong - Banten.

\section{METODOLOGI}

Prinsip dasar pengukuran logam berat dalam air menggunakan peralatan ICP-MS adalah sampel uji diintroduksikan ke dalam pusat tabung plasma argon sehingga terjadi pengabutan, kemudian secara cepat tersolvasi dan teruapkan. Ketika melewati inti plasma, proses disosiasi dan ionisasi terjadi. Ion-ion terekstrak dari tabung pusat plasma menuju suatu pompa vakum antarfase, kemudian ditransmisikan ke dalam spektrofotometer massa. Di dalam spektrofotometer massa, ion - ion terpisahkan berdasarkan massa mereka terhadap rasio muatan. Namun demikian, ion tidak dapat di pecah secara terus menerus ke dalam spektrofotometer massa. Sehubungan dengan hal tersebut, pecahan ion dari plasma harus dimodulasi dan detektor harus mampu merespon setiap perubahan dengan cepat. Peningkatan resolusi alat dengan cara melipatgandakan jalur lompatan dan tempat berhentinya ion lewat reflektor atau cermin merupakan sistem time of flight (ToF). Dengan demikian, instrumentasi ICPTOF-MS merupakan penggabungan prinsip ICP-MS dengan prinsip ToF [7].

Persiapan peralatan gelas, aquades yang digunakan, pembuatan larutan kerja logam $\mathrm{Cd}, \mathrm{Cu}, \mathrm{Mn}, \mathrm{Zn}$ dan optimalisasi ICP-ToFMS merupakan hal yang mutlak dilakukan sebelum penentuan LoQ. Semua peralatan gelas yang digunakan dalam kajian penentuan LoQ, antara lain labu ukur dan pipet, harus didekontaminasi dengan cara merendam peralatan gelas dalam aqudes yang memiliki daya hantar listrik (DHL) $<0,5 \mu \mathrm{S} / \mathrm{cm}$. Kemudian peralatan gelas dikeringkan dan dibilas dengan larutan asam nitrat grade suprapur $1: 1$, lalu dibilas dengan aquades untuk menghilangkan sisa larutan asam nitrat dan dikeringkan. Pembuatan larutan standar dilakukan dengan cara memipet masing masing larutan induk $\mathrm{Cd}, \mathrm{Cu}, \mathrm{Mn}, \mathrm{Zn}$ ke dalam labu ukur dan melarutkannya dengan aquades yang mengandung asam nitrat grade ultrapur $2 \% \mathrm{v} / \mathrm{v}$ [8]. Optimalisasi ICP-ToF-MS dilakukan sesuai manual dari pabrikan dengan menggunakan larutan tuning pada kadar 100 ppb. Tuning ICP-ToF-MS merupakan proses uji kinerja untuk mengetahui kondisi laik pakainya instrumen tersebut dengan cara membandingkan data hasil tuning dengan kriteria batas keberterimaan yang ditentukan.

Setelah persiapan dilakukan dengan baik dan benar, penentuan LoQ dilakukan dengan cara mengukur air bebas analit yang telah ditambahkan larutan asam nitrat $\left(\mathrm{HNO}_{3}\right)_{2} \%$ $\mathrm{v} / \mathrm{v}$ hingga $\mathrm{pH} \leq 2$ dan diperkaya (spike) dengan larutan standar $\mathrm{Cd}, \mathrm{Cu}, \mathrm{Mn}, \mathrm{Zn}$ pada masing masing kadar berdasarkan nilai IDL yang telah diperoleh. Nilai IDL untuk masing-masing logam berat ditentukan dengan cara mengukur air bebas analit yang telah ditambahkan asam nitrat $2 \% \mathrm{v} / \mathrm{v}$ hingga $\mathrm{pH} \leq 2$. Pengukuran air bebas analit yang diperkaya dengan larutan standar $\mathrm{Cd}, \mathrm{Cu}, \mathrm{Mn}, \mathrm{Zn}$ untuk penentuan LoQ, dilakukan pengulangan sebanyak 10 kali untuk mengetahui variabilitas dan untuk mendapatkan standar deviasi sehingga 
diperoleh LoQ [9].

Nilai IDL masing - masing analit logam diperoleh dengan mengalikan 3 standar deviasi dari minimal 10 kali pengulangan pengukuran blanko, yaitu:

$I D L=3 s d_{\text {blanko }}$

Nilai standar deviasi diperoleh dengan perhitungan, sebagai berikut:

$$
s d=\sqrt{\frac{\sum_{i=1}^{n}\left(x_{i}-\bar{x}\right)^{2}}{n-1}}
$$

dimana rerata:

$\bar{x}=\frac{\sum_{i=1}^{n} x_{i}}{n}=\frac{x_{1}+x_{2}+x_{3}+\ldots \ldots x_{n}}{n}$

Sehubungan dengan nilai IDL masih merupakan peak area, maka dilakukan pengukuran larutan standar logam $\mathrm{Cd}, \mathrm{Cu}, \mathrm{Mn}$, $\mathrm{Zn}$ dalam air pada kadar rendah yaitu setara IDL yang ditetapkan pabrikan. Penentuan kadar IDL dalam satuan $\mu \mathrm{g} / \mathrm{L}$ dilakukan melalui perbandingan larutan kerja logam Cd, $\mathrm{Cu}, \mathrm{Mn}, \mathrm{Zn}$ dalam air, adalah sebagai berikut:

$$
\operatorname{Kadar}_{I D L(\mu \mathrm{g} / L)}=\frac{[\text { Area }]_{I D L}}{[\text { Area }]_{\mathrm{stan} d a r}}[\text { Kadar }]
$$

Jika pertimbangan perbandingan estimasi limit deteksi sebagaimana dinyatakan dalam Standard Methods for The Examination of Water and Waste Water $22^{\text {rd }}$ Edition, APHA - 2012, yaitu IDL : LoD : MDL : LoQ = 1 : $2: 4: 10$ (Gambar 1), maka nilai LoQ dapat ditentukan, yaitu:

$$
L o Q=\frac{10}{1}(I D L)
$$

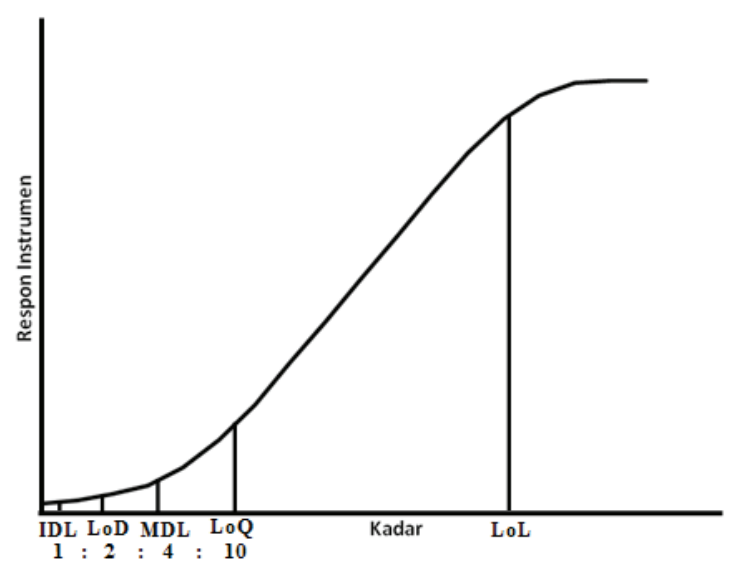

Gambar 1: Perbandingan batas deteksi dalam rentang dinamik intrumentasi

LoQ ditentukan melalui pengulangan kadar logam yang setara dengan 10 kali kadar batas deteksi instrumen. Nilai LoQ diterima jika memenuhi kriteria batas keberterimaan yaitu signal to noise ratio $(\mathrm{S} / \mathrm{N})=10-20($ Gambar 2).

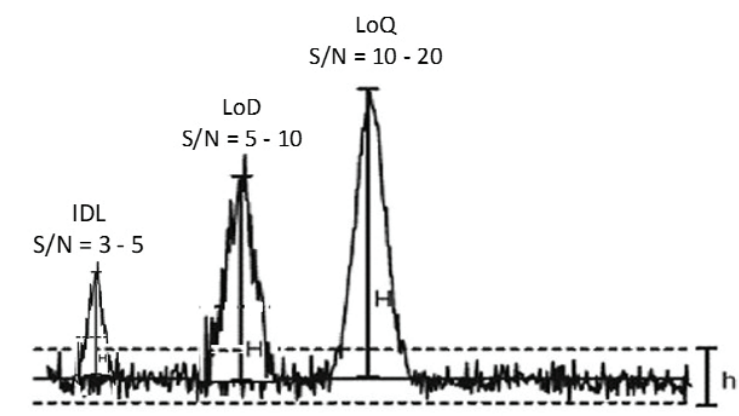

Gambar 2: Perbandingan signal to noise dalam intrumentasi

\section{HASIL DAN PEMBAHASAN}

Penentuan IDL untuk masing - masing analit $\mathrm{Cd}, \mathrm{Cu}, \mathrm{Mn}, \mathrm{Zn}$ dalam air dilakukan dengan mengaspirasikan blanko yaitu air bebas analit yang telah ditambahkan asam nitrat $2 \% \mathrm{v} / \mathrm{v}$ hingga $\mathrm{pH} \leq 2$. Pengukuran dengan ICP-ToFMS dilakukan dengan minimal pengulangan 10 kali agar diperoleh standar deviasi, sebagaimana hasil dalam Tabel 1, dibawah ini: 
Tabel 1. Nilai IDL logam $\mathrm{Cd}, \mathrm{Cu}, \mathrm{Mn}, \mathrm{Zn}$ dalam air

\begin{tabular}{ccccc}
\hline \multirow{2}{*}{ Pengulangan } & \multicolumn{4}{c}{ Analit (peak area) } \\
\cline { 2 - 5 } & $\mathbf{C d}$ & $\mathbf{C u}$ & $\mathbf{M n}$ & $\mathbf{Z n}$ \\
\hline 1 & 57.2 & 644.3 & 4058.0 & 940.5 \\
2 & 32.0 & 573.2 & 4165.7 & 684.9 \\
3 & 23.7 & 590.9 & 3752.4 & 709.2 \\
4 & 44.6 & 600.8 & 3770.8 & 685.1 \\
5 & 64.4 & 572.1 & 3820.8 & 868.8 \\
6 & 52.5 & 539.9 & 3784.7 & 783.8 \\
7 & 51.1 & 574.1 & 3740.5 & 691.9 \\
8 & 38.4 & 698.4 & 4372.0 & 733.5 \\
9 & 43.1 & 598.8 & 4240.4 & 685.7 \\
10 & 54.8 & 661.7 & 4284.4 & 735.0 \\
\hline Rerata & 46.2 & 605.4 & 3999.0 & 751.8 \\
Sd & 12.3 & 48.3 & 251.1 & 88.0 \\
IDL peak area & 37 & 145 & 753 & 264 \\
\hline
\end{tabular}

Tabel 2. Perbandingan peak area larutan standar dengan peak area IDL

\begin{tabular}{cccccc}
\hline \multirow{2}{*}{ No } & \multirow{2}{*}{ Analit } & \multicolumn{2}{c}{ Larutan standar } & \multicolumn{2}{c}{ Penentuan IDL } \\
\cline { 3 - 6 } & & Kadar $(\mu \mathrm{g} / \mathbf{L}) *$ & Rerata Peak Area & Peak Area & Kadar $(\mu \mathrm{g} / \mathbf{L})$ \\
\hline 1 & $\mathrm{Cd}$ & 0,0009 & 574 & 37 & 0,0006 \\
2 & $\mathrm{Cu}$ & 0,002 & 1682 & 145 & 0,002 \\
3 & $\mathrm{Mn}$ & 0,004 & 15375 & 753 & 0,002 \\
4 & Zn & 0,002 & 1405 & 264 & 0,004 \\
\hline *. Nilai
\end{tabular}

Semakin kecil nilai IDL, maka kemampuan peralatan lebih sensitif dalam membaca kadar analit. Namun demikian, nilai IDL dalam Tabel 1 merupakan peak area yang dihasilkan dari ICP-ToF-MS, karena itu perlu dilakukan konversi ke satuan kadar $\mu \mathrm{g} / \mathrm{L}$ dengan melakukan pengukuran larutan standar logam $\mathrm{Cd}, \mathrm{Cu}, \mathrm{Mn}, \mathrm{Zn}$ dalam air pada kadar IDL yang ditetapkan oleh pabrikan sehingga diperoleh data sebagaimana Tabel 2 .

Kadar IDL dalam satuan $\mu \mathrm{g} / \mathrm{L}$ diperoleh dengan melakukan perbandingan larutan standar yang yang telah diketahui peak area-nya, menggunakan persamaan (4) sebagaimana tersebut diatas. Contoh perhitungan IDL dalam satuan $\mu \mathrm{g} / \mathrm{L}$, adalah sebagai berikut:

$$
(\text { Kadar })_{I D L}=\frac{37}{574}(0,009 \mu \mathrm{g} / L)=0,0006 \mu \mathrm{g} / \mathrm{L}
$$

Selanjutnya, penentuan LoQ dilakukan dengan cara pembacaan pengulangan kadar 10 kali nilai IDL percobaan dan dihasilkan sebagaimana pada Tabel 3. Perkalian tersebut didasarkan perbandingan IDL dengan LoQ (Gambar 1). Nilai LoQ masing - masing logam berat $\mathrm{Cd}, \mathrm{Cu}, \mathrm{Mn}$ dan $\mathrm{Zn}$ adalah: 
Tabel 3. Perbandingan peak area larutan standar dengan peak area IDL

\begin{tabular}{|c|c|c|c|c|}
\hline \multirow{2}{*}{ No } & \multirow{2}{*}{ Analit } & \multicolumn{3}{|r|}{ Larutan standar } \\
\hline & & $\operatorname{Kadar}(\mu \mathrm{g} / \mathbf{L})$ & Peak area & Keterangan \\
\hline \multirow{10}{*}{1} & \multirow{10}{*}{$\mathrm{Cd}$} & \multirow{10}{*}{0,006} & 565.80 & \multirow{10}{*}{$\begin{array}{lr}\text { Rerata }(\mathrm{x}) \text { : } & 574,12 \\
\text { Simpangan baku }(\mathrm{sd}): & 44,59 \\
\text { Signal to Noise rasio }(\mathrm{x} / \mathrm{sd}): & 12,87 \\
\text { Batas keberterimaan: }(\mathrm{x} / \mathrm{sd})=10-20\end{array}$} \\
\hline & & & 589.10 & \\
\hline & & & 567.45 & \\
\hline & & & 499.01 & \\
\hline & & & 598.39 & \\
\hline & & & 503.27 & \\
\hline & & & 579.25 & \\
\hline & & & 591.05 & \\
\hline & & & 646.66 & \\
\hline & & & 601.21 & \\
\hline \multirow{10}{*}{2} & \multirow{10}{*}{$\mathrm{Cu}$} & \multirow{10}{*}{0,02} & 1749.41 & \multirow{10}{*}{$\begin{array}{lr}\text { Rerata (x): } & 1682,29 \\
\text { Simpangan baku (sd): } & 119,48 \\
\text { Signal to Noise rasio }(\mathrm{x} / \mathrm{sd}): & 14,08 \\
\text { Batas keberterimaan: }(\mathrm{x} / \mathrm{sd})= & 10-20\end{array}$} \\
\hline & & & 1613.01 & \\
\hline & & & 1684.21 & \\
\hline & & & 1543.45 & \\
\hline & & & 1681.76 & \\
\hline & & & 1819.59 & \\
\hline & & & 1859.04 & \\
\hline & & & 1776.99 & \\
\hline & & & 1499.67 & \\
\hline & & & 1595.78 & \\
\hline \multirow{10}{*}{3} & \multirow{10}{*}{$\mathrm{Mn}$} & \multirow{10}{*}{0,02} & 15326.70 & \multirow{10}{*}{$\begin{array}{lr}\text { Rerata }(\mathrm{x}): & 15375,13 \\
\text { Simpangan baku (sd): } & 1215,35 \\
\text { Signal to Noise rasio }(\mathrm{x} / \mathrm{sd}): & 12,65 \\
\text { Batas keberterimaan: }(\mathrm{x} / \mathrm{sd})= & 10-20\end{array}$} \\
\hline & & & 15289.60 & \\
\hline & & & 15508.15 & \\
\hline & & & 14991.99 & \\
\hline & & & 14237.34 & \\
\hline & & & 15395.34 & \\
\hline & & & 17507.78 & \\
\hline & & & 14847.57 & \\
\hline & & & 13453.56 & \\
\hline & & & 17193.24 & \\
\hline \multirow{10}{*}{4} & & & 1457.91 & \multirow{10}{*}{$\begin{array}{lr}\text { Rerata }(\mathrm{x}): & 1405,07 \\
\text { Simpangan baku }(\mathrm{sd}): & 117,00 \\
\text { Signal to Noise rasio }(\mathrm{x} / \mathrm{sd}): & 12,01 \\
\text { Batas keberterimaan: }(\mathrm{x} / \mathrm{sd}) & =10-20\end{array}$} \\
\hline & & & 1366.31 & \\
\hline & & & 1392.11 & \\
\hline & & & 1233.98 & \\
\hline & $7 n$ & 044 & 1521.89 & \\
\hline & 211 & 0,04 & 1583.22 & \\
\hline & & & 1413.44 & \\
\hline & & & 1355.70 & \\
\hline & & & 1225.15 & \\
\hline & & & 1501.01 & \\
\hline
\end{tabular}


The signal to noise ratio $(\mathrm{S} / \mathrm{N})$ yang dinyatakan dalam perbandingan antara rerata hasil pengulangan pengujian dengan simpangan baku (x/sd) harus berkisar antara $10-20$. Kisaran $\mathrm{S} / \mathrm{N}$ antara 10 - 20 berarti bahwa kadar analit mampu menghasilkan sinyal lebih besar dari blanko pada kondisi kegiatan rutin yang dapat diterapkan di laboratorium (limit of practicable, LoP). Dengan demikian, LoQ merupakan suatu batas terkecil hasil pengujian yang dapat dilaporkan (limit of reportable, LoR) dengan menyertakan nilai ketidakpastian pengukuran.

$\mathrm{S} / \mathrm{N}$ juga dapat diartikan sebagai evaluasi kesalahan acak (random error) yang terjadi pada pengujian dan perkiraan presisi yang diharapkan dari sejumlah pengulangan pengujian. Bila $\mathrm{S} / \mathrm{N}$ berkisar antara $2-3$, hal ini menunjukan batas deteksi instrumen dan bila $\mathrm{S} / \mathrm{N}$ sama dengan 5-10 maka hal ini merupakan batasan deteksi terendah (lower limit detection, LLD). Sehubungan larutan standar pada kadar 0,006 $\mu \mathrm{g} / \mathrm{L}(\mathrm{Cd}), 0,02 \mu \mathrm{g} / \mathrm{L}$ $(\mathrm{Cu}), 0,02 \mu \mathrm{g} / \mathrm{L}(\mathrm{Mn})$, dan 0,04 $\mu \mathrm{g} / \mathrm{L}(\mathrm{Zn})$ memberikan nilai $\mathrm{S} / \mathrm{N}$ dalam kisaran 10 - 20, maka dapat dipastikan bahwa kadar larutan standar $\mathrm{Cd}, \mathrm{Cu}, \mathrm{Mn}$ dan $\mathrm{Zn}$ tersebut adalah batas kuantifikasi dan dapat digunakan sebagai batasan suatu laporan [10].

Nilai LoQ dapat digunakan sebagai pertimbangan batas bawah pembuatan kurva kalibrasi. Secara kimia statistik, suatu kurva kalibrasi sebaiknya dibuat dengan satu larutan blanko dan minimal 3 kadar larutan kerja yang proposional dimana kadar larutan terendah adalah nilai LoQ, sedangkan kadar larutan kerja tertinggi sekitar 2 kali kadar sampel. Sebagai contoh pada Tabel 4 diperoleh nilai LoQ untuk elemen $\mathrm{Cd}$ adalah $0,006 \mu \mathrm{g} / \mathrm{L}$, maka jika saat melakukan pengujian sampel logam Cd dalam air atau air limbah diperoleh nilai $0,001 \mu \mathrm{g} / \mathrm{L}$, maka dilaporkan $<0,006$ $\mu \mathrm{g} / \mathrm{L}$ atau $<$ LoQ. Hal ini karena nilai 0,001 belum dapat dipastikan apakah nilai tersebut merupakan signal analit atau noise instrument [1-12].

Tabel 4. Nilai LoQ hasil percobaan di laboratorium

\begin{tabular}{cccc}
\hline No & Analit & IDL $(\mu \mathrm{g} / \mathrm{L})$ & LoQ $(\mu \mathrm{g} / \mathrm{L})$ \\
\hline 1 & $\mathrm{Cd}$ & 0,0006 & 0,006 \\
2 & $\mathrm{Cu}$ & 0,002 & 0,02 \\
3 & $\mathrm{Mn}$ & 0,002 & 0,02 \\
4 & $\mathrm{Zn}$ & 0,004 & 0,04 \\
\hline
\end{tabular}

Keunggulan penggunaan ICP-MS dibandingkan dengan instrumentasi lainnya, misalnya atomic absorption spectrophotometer, AAS, adalah kemampuan ICP-MS dalam pembacaan multi element, sensitivitas tinggi, dan informasi isotopic element. Perbandingan tersebut dapat dilihat pada Tabel 6, berikut ini:

Tabel 6. Perbandingan AAS dengan ICP-MS

\begin{tabular}{cccc}
\hline No & Uraian & AAS & ICP-MS \\
\hline 1 & Kecepatan analisis & Lama & Cepat \\
2 & Sensitivitas & Sedang & Tinggi \\
3 & Tipe pengukuran & Single elemen & Multi elemen \\
4 & Biaya & Murah & Tergantung jumlah sampel dan elemen yang diukur \\
5 & Informasi isotop & Tidak tersedia & Tersedia \\
\hline
\end{tabular}




\section{SIMPULAN}

Penentuan LoQ metode pengujian logam berat $\mathrm{Cd}, \mathrm{Cu}, \mathrm{Mn}, \mathrm{Zn}$ menggunakan peralatan ICP-ToF-MS dilakukan melalui pengulangan kadar logam yang setara dengan 10 kali kadar batas deteksi instrumen. Batasan kuantifikasi berdasarkan eksperimen diperoleh masingmasing $\mathrm{Cd}=0,006 \mu \mathrm{g} / \mathrm{L}, \mathrm{Cu}=0,02 \mu \mathrm{g} / \mathrm{L}$, $\mathrm{Mn}=0,02 \mu \mathrm{g} / \mathrm{L}$, dan $\mathrm{Zn}=0,04 \mu \mathrm{g} / \mathrm{L}$. Nilai LoQ yang diperoleh dapat digunakan sebagai pertimbangan batas bawah pembuatan kurva kalibrasi. Dengan menetapkan batas kuantifikasi, laboratorium dapat melaporkan hasil pengujian disertakan ketidakpastian pengukuran pada kadar lebih dari LoQ atau dilaporkan kurang dari LoQ pada kadar rendah, sehingga pelaporan jadi bermakna. Keunggulan penggunaan ICP-ToF-MS dibandingkan dengan instrumentasi lainnya, misalnya atomic absorption spectrophotometer, AAS, adalah kemampuan ICP-ToF-MS dalam pembacaan multi element, sensitivitas tinggi, dan informasi isotopic element.

\section{DAFTAR PUSTAKA}

(1) American Public Health Association, 2012, Standard Methods for the Examination of Water and Waste Water", 22 ${ }^{\text {th }}$ Edition, 3020 "Quality Asurance/Quality Control”, APHA, Washigton - USA;

(2) American Public Health Association, 2012, Standard Methods for the Examination of Water and Waste Water", 22 $2^{\text {th }}$ Edition, 3030 "Priliminary Treatment", APHA, Washigton USA;

(3) American Public Health Association, 2012, Standard Methods for the Examination of Water and Waste
Water", 22 ${ }^{\text {th }}$ Edition, 3125 "Metals By Inductively Coupled Plasma - Mass Spectrometry", APHA, Washigton USA;

(4) B. Magnusson and U. Omemark (eds.), 2014, Eurachem Guide, "The Fitness for Purpose of Analytical Methods - A Laboratory Guide to Method Validation and Related Topic", 2rd ed., ISBN : 978-9187461-59-0, CITAC, UK;

(5) Breton, Thomas., et. al., 2015, "Improving Precision and Signal/ Noise Ratios for MC-ICP-MS", $11^{\text {th }}$ Applied Isotope Geochemistry Conference, Published by Elseivier;

(6) Edited by Sarkar, Bibudhendra., 2002, "Heavy Metals in the Environment", ISBN: 0-8247-060-7, Marcel Dekker, Inc., New York, USA;

(7) Ellison, S.L.R., and William A (eds.), 2012, "Eurachem/CITAC Guide : Quantifying Uncertainty in Analytical Measurement" $3^{\text {th }}$ edition, ISBN : 9780-948926-30-3, CITAC, UK;

(8) GBC., 2012, “Optimass Operating Manual ICP Time-of-Flight Mass Spectrophotometer";

(9) Gupta, Vipin B. Gupta. Methods for the determination of limit of detection and limit of quantitation of the analytical methods. http://www. cysonline.org. Diunduh tanggal 13 Februari 2017;

(10) Hadi. Anwar, dkk. 2010. Pedoman verifikasi metode pengujian parameter kualitas lingkungan: Asdep Urusan Standarisasi, Teknologi dan Produksi Bersih, Deputi Bidang Pembinaan Sarana Teknis dan Peningkatan Kapasitas, Kementerian Lingkungan Hidup: Jakarta. 
(11) Thomas, Robert., 2008, "Practical Guide to ICP-MS : A Tutorial for Beginners" Second Edition, ISBN : 978-1-4200-6786-6, CRC Press Taylor \& Francis Group, Boca Raton;
(12) Wells, Greg., et. al., 2011, Technical Note Agilent Technologies, "Signal, Noise, and Detection Limits in Mass Spectrometry" Wilmington - USA; 